\title{
Expectativas y límites (subpensados) de la formación para la inserción laboral de personas inmigrantes. El caso de Barcelona 2009-2011
}

\author{
Laura C. Yufra ${ }^{1}$
}

Recibido: 01 de septiembre de 2016 / Aceptado: 09 de junio de 2017

Resumen. En el presente artículo pretendemos reconocer la incidencia de la formación para la inserción laboral, como estrategia de intervención ofrecida a la población inmigrante en la ciudad de Barcelona, durante los años 2009 y 2011. Asumimos un tipo de aproximación cualitativa a los cursos de formación que se llevan a cabo en la mencionada ciudad, realizando observaciones participantes en dichos cursos y entrevistas a los sujetos implicados. Identificamos cómo tal estrategia goza de una valoración unánimemente positiva por parte de quienes diseñan y ejecutan las políticas de formación, y esto impide una reflexión sistemática sobre sus límites. Entre ellos, los heterogéneos objetivos asignados y el papel de la estructura productiva como condicionante de sus potencialidades. Desde las prácticas concretas, emergen expectativas mucho más modestas, pero no menos valiosas, como la posibilidad de sistematizar conocimientos previos y ofrecer saberes prácticos para el desarrollo de futuros posibles trabajos. Palabras clave: expectativas modestas; formación para la inserción laboral; inmigración; límites.

\section{[en] Expectations and (unthought) limits in workforce training for immigrant people. The case of Barcelona 2009-2011}

\begin{abstract}
In this paper we aim to recognize the incidence of workforce training courses for immigrant people in Barcelona from 2009 to 2011. From a qualitative approach we conducted interviews and participating observations in these courses. We identify that this social intervention strategy enjoys a unanimous positive assessment by policymakers. In consequence, we found a lack of systematic reflection on the limits that this social intervention strategy has. For instance, the heterogeneous objectives assigned to it or the role played by productive structure as a conditioning of their potentialities. Fieldwork data reveals worth expectations about it but much more modest. That is to say, the systematization of previous knowledge and the transmission of practical knowledge for the possible future work.
\end{abstract}

Keywords: modest expectations; workforce training courses; immigration; limits.

Sumario: 1. Introducción. 2. Metodología. 3. La formación para la inserción laboral como estrategia de intervención social. 3.1. Objetivos (des)articulados de la formación para la inserción laboral. 3.2. Organización de la formación laboral. 3.3. La formación laboral dirigida a las personas inmigrantes. 4. Modulando expectativas. 4.1. La estructura productiva y la inserción laboral. 4.2. Expectativas modestas: los aportes de la formación para la inserción laboral. 5. Conclusión. 6. Referencias bibliográficas.

EU-CISOR (Unidad Ejecutora en Ciencias Sociales Regionales y Humanidades) CONICET (Consejo Nacional de Investigaciones Científicas y Tecnológicas) -UNJu (Universidad Nacional de Jujuy).

laurayufra@gmail.com 
Cómo citar: Yufra, L.C. (2018) "Expectativas y límites (subpensados) de la formación para la inserción laboral de personas inmigrantes. El caso de Barcelona 2009-2011". Cuadernos de Relaciones Laborales, 36(1), 89-106.

\section{Introducción}

El fenómeno migratorio es una de las expresiones de las inmensas desigualdades globales contemporáneas que, en los últimos años, ha adquirido una notable visibilidad. A ello ha contribuido la enorme cantidad de recursos materiales y simbólicos puestos en función del control de las fronteras, estatales y supraestatales, para "contener" las migraciones desde el denominado Sur del mundo hacia el Norte. Ahora bien, es preciso notar que, además de las políticas de control, los estados desarrollan políticas de integración dirigidas a la inmigración y que, junto con las políticas de cooperación al desarrollo, conforman el conjunto de las políticas migratorias (López Sala, 2005).

En el presente trabajo, nos focalizaremos específicamente sobre la formación para la inserción laboral como estrategia de intervención con el colectivo de personas inmigrantes. Para llevar a cabo tal especificación, no obstante, deberemos identificar también algunas características generales de la formación para la inserción laboral en general. Cuando se dirige a las personas inmigrantes, dicha estrategia se encuentra entre las políticas dirigidas a favorecer su integración y, consecuentemente, forman parte de los recursos del Estado de bienestar.

En el caso español, nos encontramos con un tipo de Estado de bienestar que ha sido denominado familista o mediterráneo (Ferrera, 1996; Moreno, 2002). Tal denominación señala el rol ocupado por las familias, que en otros sistemas de bienestar es cumplido por el mercado o el Estado. Vicenç Navarro (2006) se refiere al "subdesarrollo" del Estado de bienestar español, para marcar las deficiencias de las prestaciones sociales ofrecidas por éste, en comparación con otros modelos, así como el solapamiento entre el desarrollo de las políticas públicas distributivas y las restricciones de las mismas. Ahora bien, es conocido que los diferentes Estados de bienestar asignan, también de modo diferencial, recursos y prestaciones a las personas inmigrantes (Sainsbury, 2006). Por lo tanto, las deficiencias que caractericen a las prestaciones dirigidas a la población en general serán compartidas por aquellas dirigidas a las personas inmigrantes.

Refiriéndose a la forma de concesión del bienestar, Miguel Laparra (2003) destaca la elección del principio de subsidiariedad por parte del Estado español para la prestación y distribución de recursos dirigidos a la población inmigrante. En este sentido, es paradigmática la participación de actores no gubernamentales en la implementación y el desarrollo de estas políticas. Dicha situación conlleva específicas consecuencias señaladas por Albert Mora (2006):

Esta cesión de competencias implica una debilitación de la misma idea de "derecho", puesto que las diversas prestaciones adquieren carácter graciable y dejan de ser consideradas como instrumentos de garantía de derechos reconocidos. $\mathrm{La}$ deriva de parte de las ONG hacia el funcionamiento como "empresas de servicios" debilita, además, el potencial transformador de las mismas y su papel de contesta- 
ción frente a la dejación de las Administraciones por lo que respecta a la atención de los colectivos excluidos. (Mora, 2006: 28-29).

Han sido señaladas las dificultades producidas cuando el Tercer Sector es el encargado casi exclusivo de ofrecer prestaciones a las personas inmigrantes. No sólo las que acabamos de mencionar en la precedente cita. Otros trabajos identifican la falta de coordinación de las tareas que realiza el Tercer Sector (Carrasco, Ruiz y Martínez, 2006; Aguilar, 2011). Asimismo, ha sido analizado el papel que cumplen las subvenciones en los modos de funcionamiento de las políticas públicas. Por ejemplo, la dificultad en mantener posiciones críticas hacia las entidades financiadoras, porque dichas subvenciones producen relaciones de "dependencia" para el funcionamiento de las entidades del Tercer sector (Casey, 1995; Rodríguez Cabrero, 2003; Alonso, 2007; Oliver Grasiot, 2015 entre otros).

En el ámbito de la formación para la inserción laboral de las personas inmigrantes, es posible encontrar una serie de dificultades particulares, además de las apenas citadas. En otro lugar hemos analizado algunos rasgos del funcionamiento de la formación laboral dirigida a las personas inmigrantes y los requisitos para el acceso a dicha formación (Yufra, 2012). En este trabajo pretendemos, en cambio, analizar las expectativas y los límites de la estrategia de la formación para la inserción laboral de las personas inmigrantes.

Con respecto al marco temporal abordado, el trabajo de campo coincide aproximativamente con el inicio de la crisis económica-financiera. Este hecho permite echar luz sobre esta estrategia de intervención que apunta a la mejora de las competencias de los individuos, en un contexto de altos índices de destrucción del empleo, que afectó fundamentalmente a la población inmigrante (Sanahuja i Velez, 2010). A largo del periodo trabajado, la estrategia de intervención mencionada demostró tener un enorme consenso acerca de su pertinencia. Por otro lado, consideramos que, en la actualidad, esas unánimes expectativas acerca de la capacidad de la formación para la inserción laboral permanecen. A nuestro entender, tales expectativas producen dificultades a la hora de reconocer con claridad los límites de dicha estrategia.

A la luz del material empírico recogido, parece mucho más adecuado matizar la confianza en la capacidad de la formación para la inserción laboral. En tal sentido, nos encontramos en la misma línea de trabajo de Darmon et al. (2006) quienes sostienen que los enfoques consensuales de las políticas activas de empleo y, particularmente, los que se ocupan de la formación para la inserción laboral, merecen contrastarse con estudios empíricos. Estos estudios pueden ofrecer una imagen mucho más modesta, pero también muy incisiva, de la capacidad de la formación para la inserción laboral como estrategia de intervención social.

\section{Metodología}

En el trabajo de campo realizado, hemos llevado a cabo una aproximación de tipo cualitativo a los cursos de formación que se llevan a cabo en la ciudad de Barcelona. Suscribimos la propuesta de Shore y Wright (1997) de efectuar una antropología de las políticas, al considerarlas como textos culturales a ser interpretados, y también como dispositivo que establece clasificaciones, en el caso que estamos considerando, clasificaciones poblacionales. 
Esta aproximación nos ha permitido comprender e interpretar los sentidos que se le conceden a la formación, tanto por parte de quienes están involucrados en la formación para la inserción laboral de las personas inmigrantes, como por los documentos que expresan los lineamientos de dichas políticas.

Hemos realizado el trabajo de campo en nueve entidades que aceptaron participar en él. La elección de las mismas se llevó a cabo siguiendo el criterio de máxima variabilidad de la muestra, atendiendo a lo señalado por Daniel Berteaux (2005). Es decir, buscamos que las entidades tuvieran formas organizativas diferenciadas tales como asociación, fundación, cooperativa, ONG y también acudimos a la Agencia municipal Barcelona Activa. Asimismo, tales organizaciones tenían diferentes vinculaciones con otras entidades del tejido social. Encontramos, pues, lazos de dichas entidades con la Iglesia católica, con un sindicato o con el movimiento vecinal.

Hemos realizado observaciones participantes de un curso completo sobre "Cuidados del hogar" y asistido a sesiones de cursos de soldadura, pintura y albañilería en diferentes entidades. Asimismo, hemos conducido entrevistas informales y semi-estructuradas con coordinadores de la formación, con formadores y con personas inmigrantes que llevaban a cabo la mencionada formación. Hemos realizado veintisiete entrevistas en total. Por otro lado, hemos llevado a cabo el análisis documental de planes locales y autonómicos de integración y de periódicos relacionados con el tema. El trabajo de campo se realizó entre 2009 y 2011. La aproximación cualitativa en la que se enmarca el trabajo propone que la finalización de la investigación se produce en el momento de la saturación de la información obtenida (Berteaux, 2005).

Consideramos que, a pesar de que han transcurrido unos años desde el trabajo de campo, las conclusiones pueden indicar tendencias que permanecen en la actualidad, esto es, la enorme confianza en la formación para la inserción laboral de las personas inmigrantes $y$, paralelamente, el menor peso concedido a la reflexión acerca de sus límites.

Como acabamos de sostener, este trabajo se centra en la ciudad de Barcelona ya que hicimos nuestro trabajo de campo en las entidades territoriales de la ciudad. Ahora bien, las personas entrevistadas, muchas veces, se refieren a ámbitos más amplios, ya sea la Comunidad Autónoma o el Estado. Por ello, en los fragmentos de entrevistas que transcribimos a continuación es posible encontrar dichas referencias geográficas más amplias.

\section{La formación para la inserción laboral como estrategia de intervención social}

A lo largo de la historia contemporánea, y desde diferentes posiciones ideológicas, se ha colocado a la educación en una posición ejemplar por su capacidad de "solucionar" todo tipo de problemas (Fernández Enguita, 1990). La formación para la inserción laboral también comparte esta caracterización que la señala como un potencial solucionador de "problemas" sociales².

Para una distinción entre problema social y sociológico véase el trabajo de Encarna Herrera (1994). Asimismo, la perspectiva de análisis que asumimos permite reconocer que desde las políticas públicas se define un problema y se perfila su solución, según los conceptos e imágenes empleados en dicha definición (Shore Wright, 1997). 
Esta estrategia de intervención social se engloba dentro de las políticas activas de empleo que se han vuelto una herramienta privilegiada tanto en el ámbito estatal como en el de la Unión Europea. Específicamente, en el ámbito comunitario se puede constatar una confluencia en la adopción de medidas de este tipo (Moreno y Pascual Serrano, 2007). Dicha estrategia se encuentra emparentada con la crisis del principio integrador del trabajo bajo la condición salarial (Castel, 1997) y las formas flexibilizadas de las relaciones laborales con fuerte impacto en la vida social (Sennett, 2000; Alonso, 2007).

Con la crisis económica financiera desatada durante el 2008 y sus preocupantes índices de desempleo y pauperización social, la formación para la inserción laboral aparece como una medida a implementar para salir de ella, atendiendo a las exigencias de la sociedad del conocimiento y las nuevas tecnologías ${ }^{3}$.

Desde nuestro punto de vista, estas expectativas hacia la estrategia de intervención de la formación para la inserción laboral requieren ser revisadas. Para ello, pasaremos primero a desglosar los objetivos de la formación que se presentan como articulados; a definir cómo es la organización del sistema de formación actualmente y, por último, a señalar qué se espera de la formación para la inserción laboral dirigida específicamente las personas inmigrantes.

\subsection{Objetivos (des)articulados de la formación para la inserción laboral}

Para empezar, deberíamos reconocer dos objetivos de la formación para la inserción laboral que parecieran confluir de modo implícito, pero que, más bien, requieren ser analizados críticamente. Uno de ellos sostiene que la formación responde al derecho de todos los ciudadanos a continuar con el aprendizaje a lo largo de la vida. Desde este punto de vista, se trata de la posibilidad de obtener nuevos conocimientos una vez que ha finalizado la escolarización obligatoria. La opción de continuar formándose haría posible el despliegue de las potencialidades de los sujetos en todas sus dimensiones; conseguir tal despliegue, debería constituir un objetivo de los gobiernos democráticos.

El coordinador de Formación Profesional para el Empleo de un centro vinculado a un sindicato sostiene que el acceso a la formación promueve la igualdad de oportunidades. Así lo señala:

El sindicato y el centro de formación, considera que la formación es un elemento para igualar la oportunidad, dentro del sector y la empresa y, por lo tanto, nuestras políticas van dirigidas a las personas que están más desiguales de alguna manera en el mercado de trabajo [...] porque eso está en el ADN nuestro, en los cromosomas de un sindicato está, como elemento central, está la igualdad de oportunidades. (Entrevista al coordinador de la Formación Profesional de una fundación vinculada a un sindicato).

\footnotetext{
Tal como se señala desde el Ministerio de trabajo e Inmigración; “[ ] una de las cosas que ha puesto de manifiesto la crisis es la 'necesidad' de formar más a los ciudadanos, por lo que es preciso abordar la mejora de incentivos e inversiones en nuevas cualificaciones. La agenda para nuevas cualificaciones y empleos de la UE es una de las iniciativas fundamentales para modernizar el mercado laboral, facilitando la movilidad de los trabajadores, desarrollar cualificaciones a lo largo de la vida del trabajador y adecuar mejor la oferta a la demanda". (Diario Electrónico del Gabinete de Comunicación Ministerio de Trabajo e Inmigración, 2010).
} 
Esta referencia, de alguna manera, introduce elementos contextuales en los que se desarrolla la formación, esto es, las empresas y el mercado laboral; no obstante, se entiende que la formación constituye un beneficio para las personas que la realizan.

El segundo objetivo de la formación supone colmar las exigencias del mercado laboral en constante cambio. Desde este punto de vista, los sujetos deben adaptarse a las demandas de un mundo laboral cada vez más exigente y competitivo. Los cambios en los modos de producción y reproducción económica exigirían como contrapartida la formación continua de los sujetos que intervienen en dichos procesos ${ }^{4}$. Así pues, la formación no surgiría de una necesidad de los sujetos sino desde las demandas de la estructura productiva.

Como veremos más adelante, estos objetivos diversos y yuxtapuestos no siempre coinciden, a pesar de que diferentes actores asuman implícitamente que sí lo hacen. Tal falta de confluencia se hace patente cuando se reflexiona desde las prácticas de inserción laboral, como veremos más adelante.

\subsection{Organización de la formación laboral:}

En el caso español, es preciso reconocer la doble estructura organizativa. La Formación Profesional de Grado Medio y Superior, forma parte de la formación reglada y depende del Departamento de Educación. Por otro lado, la Formación Profesional para el Empleo depende del Departamento de Trabajo y del Servicio de Ocupación, y se engloba dentro del ámbito de la formación no reglada. Esta última se subdivide, a su vez, en la llamada Formación Continua o Formación Permanente, dirigida a los trabajadores para promover la formación a lo largo de la vida, articulada con los planes de formación intersectoriales o sectoriales; y la llamada Formación Ocupacional o Formación para el Empleo, impartida a los trabajadores en paro que buscan en la formación el modo de (re)incorporarse al mercado de trabajo. Así pues, la misión de la Formación Continua es proporcionar a los trabajadores ocupados la formación que necesiten a lo largo de su vida laboral, aportándoles conocimientos y experiencias adecuadas a las competencias demandadas en cada momento por las empresas y por el mercado laboral en general. La Formación Ocupacional apunta a la posibilidad de adquirir nuevas cualificaciones por parte de las personas desocupadas para poder reinsertarse en el mercado laboral ${ }^{5}$.

El Centro Europeo para el Desarrollo de la Formación Profesional (CEDEFOP) sostiene que, "Nuevas ocupaciones y nuevas cualificaciones están emergiendo, en la medida en que la tecnología, la innovación, el cambio demográfico y las estrategias climáticas generan nuevas demandas" (Citado en Diario Electrónico del Gabinete de Comunicación Ministerio de Trabajo e Inmigración, 2010).

5 Desde el año 2007, luego de fusionarse con la fundación Forcem, la Fundación Tripartita para la Formación para el Empleo (que abarca la Formación Continua y la Formación Ocupacional), gestiona la Formación para el Empleo. Dicha fundación perteneciente al Sector Público Estatal es uno de los órganos que componen la estructura organizativa y de participación institucional del subsistema de Formación para el Empleo. Tiene carácter tripartito porque su patronato está constituido por la Administración Pública y por las organizaciones empresariales y sindicales más representativas. Sus objetivos son: asistir técnicamente al Servicio Público de Empleo Estatal; contribuir al impulso y difusión de la Formación Profesional para el Empleo entre empresas y trabajadores; prestar apoyo técnico a las Administraciones Públicas y a las organizaciones empresariales y sindicales presentes en los órganos de participación del sistema. Los recursos que financian el sistema de Formación Profesional para el Empleo proceden de la recaudación de la cuota de formación profesional que realiza la Seguridad Social, de las ayudas del Fondo Social Europeo y de las aportaciones específicas establecidas en el presupuesto del Servicio Público de Empleo Estatal (Fundación Tripartita, 2010). 
La diferente dependencia ministerial mencionada incide en la validez de las certificaciones a las que da derecho la realización de un determinado curso. Así lo señala el coordinador de la Formación Profesional para el Empleo, en relación con la motivación de las personas para llevar a cabo dicho tipo de formación:

[...] los certificados que hacemos desde la Formación para el Empleo no tienen valor académico [...] se está trabajando para que estos certificados, este de cuarenta horas, que lo tengas en la mochila como itinerario para sumarlo, poder llegar a hacer un módulo de estos [formación reglada] y que tengan correspondencia, que se igualen [...] lo que va determinar el valor... cuando estas cosas tienen valor, cuando tienen valor social y cuando tienen valor en la empresa. $\mathrm{Y}$ cuando lo tengan, pues la gente hará formación. (Entrevista al coordinador de la Formación Profesional de una fundación vinculada con un sindicato).

A esta compleja organización podemos agregar las Escuelas de Adultos, los programas de Garantía Social (dependientes del Ministerio de Educación) y los programas propios de las entidades del Tercer Sector. En relación con esta compleja trama institucional existen trabajos que señalan la falta de coordinación del sistema (Aguilar Idánez, 2011; Carrasco, Ruiz y Martínez, 2006; Valiente, Zancajo y Tarriño, 2014). Elocuentemente, Aguilar Idánez sostiene:

La Formación Profesional de Base (competencia del Ministerio de Educación y CC.AA. [Comunidades Autónomas]) y la Formación Profesional Ocupacional (competencia del Ministerio de Trabajo y CC.AA.), ya bastante descoordinadas y de espaldas entre sí, coexisten en no pocos municipios con otros sistemas locales de formación. Y si añadimos a la lista los programas de Garantía Social (competencia de Educación), la Educación de Adultos (competencia de Educación y los ayuntamientos en no pocos casos), los programas de Formación Continua fruto de los acuerdos entre patronal y sindicatos (competencia de la Fundación Tripartita), vemos que lo que falta no es oferta (seguro que ésta es tan excesiva como inadecuada a las necesidades del mercado laboral) sino que falta coordinación, cohesión y sensatez (2011: 9).

\subsection{La formación laboral dirigida a las personas inmigrantes}

Específicamente, en relación con las personas inmigrantes, también se espera que la formación para la inserción laboral tenga un papel muy importante ${ }^{6}$. En este sentido, la formación para la inserción laboral es considerada como clave para la integración de las personas inmigrantes. El Plan Estratégico de Ciudadanía e Inmigración (PECI) señala:

Podemos decir también que la mejora en el nivel formativo será un requisito para la mejora en el empleo. Por todo ello, las políticas de formación-empleo se desa-

Por otra parte, es preciso señalar que el fenómeno migratorio aún se encuentra estrechamente vinculado con la idea del migrante trabajador cuya presencia sólo se encuentra justificada en tanto que tal y, en consecuencia, por los aportes que pueda ofrecer a la sociedad de instalación (Sayad, 2010; Santamaría, 2007). Dicha imagen persistente no parece ser permeable a las enormes tasas de desempleo que padecen las personas inmigrantes. 
rrollan precisamente para conceder capacitación profesional a colectivos, entre ellos al inmigrante, para facilitar tanto su inserción laboral como social (PECI, 2011: 127).

En el fragmento señalado se patentiza cómo se le atribuye a la formación la mejora de la situación en dos planos, el laboral y el social. La mejora sobre el primer plano también es señalada por Miguel Pajares quien afirma: "Las actuaciones de tipo formativo, es decir, las dirigidas a la formación profesional y ocupacional de las personas inmigradas son, sin duda, de gran importancia para su inserción laboral" (Pajares, 2005: 215). Con respecto al plano social, el Plan Estratégico de Ciudadanía e Inmigración, sostiene que llevar a cabo un proceso formativo mejora la situación social de las personas inmigrantes: "La formación permanente es hoy en día un requisito imprescindible para impedir la aparición y consolidación de fracturas sociales." (PECI, 2007: 229). El Informe sobre la situación de integración social de los inmigrantes y refugiados en 2008 enmarca a la formación para la inserción laboral como parte de las políticas activas. Dicho informe sostiene: "La formación es uno de los factores que contribuyen a crear oportunidades para los trabajadores, un elemento principal de las políticas activas de empleo." (Foro para la Integración Social de los Inmigrantes 2008: 65).

Llama la atención el peso otorgado a la formación, cuando es conocida la situación de desventaja que supone la condición migrante. En este mismo sentido, la mencionada política aparece como la que ofrecería la oportunidad de ascenso social superador de las restricciones impuestas por las políticas de control de flujos migratorios, las cuales relegan a las personas inmigrantes a las posiciones más desfavorables dentro del mercado laboral: "se hace hincapié en la formación como instrumento para ampliar sus posibilidades de promoción y movilidad profesional, con el fin de contrarrestar la tendencia hacia una estratificación étnica y de género del mercado laboral" (PECI, 2007: 240). Así pues, a través de la formación se espera atenuar la etnoestratificación y segmentación por género del mercado laboral.

Ahora bien, esta manera de concebir a la formación deja invisibilizada la configuración política del mercado laboral, que es señalada por Sandra Gil Araujo:

En el caso español, la cláusula de prioridad nacional, junto con la política de contingentes o cupos laborales supone el otorgamiento de permisos de residencia y de trabajo restringidos a determinados sectores laborales. Esto coloca a los trabajadores inmigrantes en un número limitado de actividades: servicio doméstico, agricultura, construcción, hoteles y restaurantes, que han sido los más afectados por el proceso de desregulación (Gil Araujo, 2010: 120).

Justamente, María García-Cano Torrico advierte cómo la expectativa reparadora puesta en las políticas de formación hacia las personas inmigrantes -y la concepción de que es necesaria la intervención social sobre el colectivo inmigrante- pone de manifiesto que las leyes de control de flujos migratorios colocan a los inmigrantes en una posición de desventaja social:

En el caso de la población trabajadora extranjera la puesta en marcha de actuaciones de formación ocupacional, como medidas de promoción de la igualdad de oportunidades, debe ser reconocida como el resultado del no-reconocimiento de 
derechos, o de la incapacidad por parte del país receptor de promover un sistema lo suficientemente eficaz como para garantizar la igualdad de recursos y beneficios sociales de los que sí disfruta la población trabajadora nacional (García-Cano Torrico, 2002: 331).

Como señalamos más arriba, existen concepciones muy optimistas en relación con la potencialidad de la formación para la inserción laboral, esto es, que mediante ella, se podrá conseguir un empleo, que cuanta mayor sea la formación, mejor será dicho empleo. Y además, que tal empleo producirá integración social.

Los trabajos académicos citados, por el contrario, señalan claros límites a las expectativas definidas en los planes de integración acerca de la política de formación para la inserción laboral de los inmigrantes. La normativa migratoria, como acabamos de señalar, establece un marco de posibilidades limitadas para la inserción laboral de las personas inmigrantes. Precisamente en dicha relación, es decir, en los marcos de la política de control de flujos migratorios, es preciso pensar las políticas de formación dirigidas a la inmigración, para así poder reconocer mejor su alcance.

\section{Modulando expectativas}

\subsection{La estructura productiva y la inserción laboral}

Hemos señalado la importancia de las leyes de extranjería que establecen mecanismos regulatorios sobre las personas que pueden acceder al territorio nacional-estatal y comunitario, sujetos a la definición de ámbitos específicos en los que pueden desarrollar sus actividades.

Ahora bien, cuando analizamos la formación para la inserción laboral, es preciso señalar también la incidencia de la estructura productiva en sus posibilidades de desarrollo. Así pues, desde una de las fundaciones que imparte Formación Profesional se aproxima una reflexión central, no abordada sistemáticamente, acerca de la escasa importancia que el sistema productivo español y catalán le ha dado a la formación: “[...] la manera de gestionar las empresas en Catalunya y en España [...] la formación no es un elemento central del crecimiento, del desarrollo empresarial." (Entrevista al coordinador de la Formación Profesional de una fundación vinculada con un sindicato). Según lo señalado, en el caso que nos ocupa, el tipo de actividad productiva llevada a cabo en las empresas no requiere de la formación como un elemento prioritario y, por lo tanto, los empresarios no están interesados en facilitar a sus trabajadores la posibilidad de acceder a cursos de formación 7 .

\footnotetext{
Dentro de la órbita del sindicato funciona también un servicio lingüístico para promover el aprendizaje de la lengua catalana. La coordinadora de dicho servicio nos comenta una experiencia piloto de la enseñanza del catalán en las empresas. Sin embargo, la evaluación que se realiza no es completamente positiva: "Pero eran cursos que se hacen en la empresa, que se hicieron en las empresas del sector cárnico que tienen un porcentaje altísimo de trabajadores extranjeros, entonces, sí que eran cursos de formación básica de lengua catalana, de niveles incluso de acogida lingüística y de nivel básico que la empresa los quería hacer, para poder comunicar con estos trabajadores unos mensajes principales de comunicación entre trabajador y empresa. Pues estos cursos se han ido haciendo. Hay una valoración diversa de estos cursos. Hubo determinados problemas, hubo algunas empresas que se implicaron más, y otras, que no se implicaron tanto, y tuvimos un funcionamiento irregular. En principio, hay empresas que todos los trabajadores pudieron continuar el curso, y otros, que las necesidades de
} 
Por otra parte, en la misma entrevista, se señala que en determinados sectores productivos las competencias requeridas para llevar a cabo el trabajo en ellos son mínimas.

Claro, este grupo de trabajadores del sector cárnico, el trabajo que hacen en la cadena de producción cárnica es un trabajo muy poco especializado, muy poco especializado. Se dedican a tareas muy poco cualificadas donde el crecimiento de la empresa no viene tanto determinado por el tipo de producto final que hace esa empresa, por la calidad de ese producto y por el valor añadido que tenga ese producto, sino por la cantidad de cosas que haga, por la cantidad de... no es un producto de calidad, entonces, las personas que trabajan en esa línea tienen muchas dificultades para formarse. Hacen lo básico. Curso de manipulador de alimentos, cosas muy básicas que no les va a permitir cambiar de sector. (Entrevista al coordinador de la Formación Profesional de una fundación vinculada con un sindicato).

Por lo recién dicho, se encuentra un límite a la relevancia concedida a la necesidad de formación ya que existen amplios ámbitos laborales que no requieren de ella. Es preciso tener en cuenta la existencia de puestos de trabajo que demandan poca calificación, tal es el caso recién señalado, en el que el entramado empresarial otorga prioridad a la producción en cantidad (y no en calidad) y que son los sectores en los que se insertan las personas inmigrantes ${ }^{8}$. Así pues, encontramos que las expectativas generadas por la formación laboral encuentran un límite en relación con la trama empresarial presente en el territorio.

En la siguiente cita se destaca que el tipo de trama empresarial es el marco al que hay que ajustarse:

[...] nosotros por mucho que consultemos a la estructura sindical, nuestra consulta y nuestras propuestas a fines de formación, en principio, tiene que encajar o debería encajar con la propuesta que más o menos determina la Administración, porque en Catalunya pues tiene un determinado tejido económico, tiene un determinado

producción de la empresa, en el momento no permitían que el trabajador pudiera ir al curso y se tenía que primar la producción, y entonces esto también falló. También fallaron otros temas de funcionamiento, y el resultado ha sido un poco irregular, en función de la implicación de la empresa también [...] pensamos que es una experiencia muy importante porque por primera vez se han hecho cursos en el marco de la empresa, la empresa ha facilitado una parte de la jornada laboral de estos trabajadores para hacer este curso y esto es muy positivo, pero entendemos que tiene que haber una continuidad y que se tiene que ver que estos cursos no acaban en cuarenta y cinco horas, sino que tiene que haber una trayectoria formativa porque estas personas puedan hacer todo un itinerario en lengua catalana o incorporarse después en el circuito de la formación en lengua catalana que se ofrece en la localidad. Esto quiere decir que un trabajador de estas empresas pueda encontrar un estímulo participando en un curso en el marco de la empresa, pero tendríamos que asegurar que esta persona continúa la formación o en el consorcio de la localidad o de otras maneras, o potenciar que dentro de la misma empresa se continúe también todo un itinerario y aquí, todavía, esto lo tenemos pendiente" (Entrevista con la coordinadora del Servicio Lingüístico que funciona en lo marco de un sindicato). Ciertamente, este es un complejísimo tema ya que atraviesa el conflicto nacional catalán, cuya caracterización excede largamente las posibilidades de este artículo. Sin embargo, sirve para reconocer las dificultades de las empresas en promover actividades formativas que no tengan un efecto inmediato en su productividad.

8 En el mismo sentido se expresa el estudio de Valiente, Zancajo y Tarriño, que destaca la insuficiencia del sistema productivo: "La política económica debería favorecer la transformación del tejido empresarial hacia un tejido intensivo en tecnología y conocimiento" (2014: 195. La traducción es nuestra). En el mencionado estudio también se señalan dificultades específicas según el tamaño de la empresa en cuestión. 
tejido industrial, tiene un determinado perfil de personas que están trabajando, tiene un determinado perfil de personas que están en paro, y a partir de ahí, la Administración elabora una propuesta de acciones donde en principio los centros de formación que colaboramos con la Administración en ejecución de formación debemos estar en ese círculo. [...] tanto en la formación específicamente para parados o la específicamente para personas ocupadas, siempre aparece un listado de acciones que, en principio, hay que rellenar. En principio, unas acciones prioritarias. (Entrevista al coordinador de la Formación Profesional vinculada a un sindicato).

Aunque en la precedente cita no sea reconocido, existe una tensión discursiva. Por un lado, como señalamos en el apartado sobre los objetivos de la formación, se supone que esta debe responder a las necesidades formativas de los sujetos quienes, mediante la obtención de nuevos saberes y competencias, contarán con mayores posibilidades de mejoras laborales y de condiciones de vida. Otro supuesto, como dijimos, tiene que ver con que la formación continua encuentra su motivación en una estructura productiva que constantemente introduce dichos conocimientos en su forma de producir.

En lugar de ver confirmadas tales expectativas, nos encontramos con que la producción empresarial, como los ejemplos precedentemente señalados, puede requerir saberes y competencias mínimas. Es decir, la importancia concedida a la formación omite esta referencia ineludible: si se pretende una formación que atienda a las demandas productivas, éstas no pueden ser de cualquier clase, sino de una que tenga en los avances y mejoras del conocimiento el eje de su desarrollo.

Por otra parte, en el caso de las personas inmigrantes, las imposibilidades del despliegue de las potencialidades de la formación se ven redobladas ya que se suma la referencia a la necesidad de inserción laboral inmediata (sujeta también a la cuestión legal señalada más arriba), donde los ámbitos de inserción son sumamente limitados y de baja calificación laboral. Así, la oferta formativa se ve reducida a las posibilidades concretas que las personas inmigrantes tendrán, según un mercado laboral muy estrecho (García-Cano Torrico, 2003; Yufra, 2016).

Pero además de esta limitación, el empresariado, también condiciona el acceso a la formación. Es decir, no sólo se desconoce a la formación un motor para el desarrollo de mejoras productivas; en ocasiones, por el contrario, se lo identifica como un obstáculo o una competencia para el funcionamiento de la producción. Así lo señala el coordinador de la formación sindical:

En el tema del acceso a la formación, cada vez es mayor, porque bueno, se ha convertido un poco en uno de los ejes y más en estos tiempos de crisis y tal, pues se acude mucho a la palabra formación para reciclarse, para tener un mejor acceso al empleo, para la permanencia en el empleo y demás, lo que pasa es que sí que es verdad, con respecto al acceso a la formación, muchas veces las empresas [ponen] problemas [...] (Entrevista al coordinador de la Formación Sindical).

Por último, quisiéramos agregar un aspecto subpensado desde los análisis críticos y reflexivos acerca del empresariado en su vinculación con la formación para la inserción laboral. Como hemos señalado, existen trabajos que indican algunos efectos nocivos en las formas de funcionamiento de las políticas públicas mediante 
subvenciones. Ahora bien, estas subvenciones difícilmente son reconocidas como una "ayuda" concedida a las empresas. Por el contrario, es hipervisibilizada la "ayuda" que esta posibilidad de acceder a formación y a prácticas de inserción representa para las personas inmigrantes.

Esta dinámica hace que se destinen recursos públicos al sector privado, a través de las subvenciones concedidas a la formación para la inserción laboral de personas inmigrantes y la inserción laboral, sin el suficientemente reconocimiento social de dicha transferencia. Veamos un caso encontrado en el trabajo de campo. En él, una empresa se propone como centro de prácticas, produciéndose previamente una selección de las personas más idóneas9. Una técnica sostiene cómo ofrecen este servicio de modo gratuito a las empresas:

Entonces lo que nosotros hicimos es crear toda una red de empresas con las que trabajamos todavía, nosotros hacemos una preselección aquí, en función del perfil que nos pide la empresa y enviamos personas. El servicio es obviamente gratuito para las empresas y para los usuarios. (Entrevista coordinadora ONG con servicio de primera acogida).

En la misma línea que el precedente ejemplo, las entidades ofrecen a las empresas como posibles empleados a las personas que llevan a cabo la formación. Por lo tanto, las empresas no deberán invertir en la formación de estas personas, en caso de contratación. El ejemplo que sigue es paradigmático ya que da un paso más allá de la dinámica apenas descripta:

[...] la fundación HDM funciona como una ONG, y entonces el Centro Abierto diríamos que el área del Centro Abierto lo patrocina una fundación social de la empresa, X SEGUROS, nos dan ayuda, apoyo económico, apoyo con lo que es material, infraestructura, y demás, entonces lo que pasa, que tenemos contacto directo con esta empresa de seguros $\mathrm{X}$, que funciona, es una gran plataforma de atención al cliente y call center, pues es un puente interesante porque primero dan formación, vienen personas formadoras profesionales de la empresa $\mathrm{X}$ a darnos la formación de atención al cliente, luego también hacemos, seleccionan los mejores alumnos, los que creen que cumplen el perfil e hicieron prácticas, también en Sant Cugat y después por futuras o posibles futuras inserciones que pueda haber, tener un contacto directo, y un poco va de esto [...] son cursos que nosotros ofrecemos gratuitamente, porque vienen subvencionados. (Entrevista a la coordinadora de una fundación privada que imparte un curso de "Atención al cliente").

La posibilidad de realizar una "formación a medida" de posibles futuros empleados, constituye un aporte a la empresa que queda ciertamente opacado. Asimismo, la formación la imparten profesionales de dicha empresa, que es financiada con fondos públicos. Por lo tanto, dichos fondos hacen un aporte casi directo a la mencionada empresa:

Después hacemos el módulo de "Atención al cliente y call center" que consta de horas teóricas aquí en la fundación por un formador profesional de la empresa $\mathrm{X}$

Sobre algunos efectos de la selección de las personas que realizan la formación por parte de los centros puede consultarse el ya citado trabajo de Darmon et al. (2006). 
seguros, o sea la misma formadora, es una chica, que forma los futuros empleados de X, también se dedica a la formación, es una persona totalmente profesional del ámbito, hacemos algunas [de las horas] de la formación teórica in situ, y entonces un día se van todos de excursión hasta Sant Cugat y allá ven todo, la plataforma del call center y se los dejan estar incluso haciendo un poco de prácticas, para que los vean cómo trabajan. (Entrevista a la coordinadora de una fundación privada que imparte que imparte un curso de "Atención al cliente").

Así vemos cómo se produce una invisibilización de la transferencia de recursos públicos al empresariado al ofrecerles servicios de selección de personal o personal para la realización de prácticas en dichas empresas. Si no existieran las subvenciones públicas, las empresas deberían pagar tales servicios. Debido a un efecto de inversión, las ayudas concedidas por las subvenciones aparecen como dirigidas exclusivamente a las personas inmigrantes quedando completamente en las penumbras su efecto en las empresas.

\subsection{Expectativas modestas: los aportes de la formación para la inserción laboral}

Según lo que nuestros entrevistados nos relataron, muchas veces, la formación se lleva a cabo no tanto por un interés en ella, sino por el hecho de encontrarse en una situación de desempleo ${ }^{10}$. Al contrario de lo que se podría suponer, esta situación no hace que la valoración por parte de las personas que realizan los procesos formativos sea negativa. De hecho, en nuestras entrevistas pudimos recoger opiniones muy positivas de la formación recibida. Esto se debe, por un lado, a que las certificaciones que puedan obtener en los recorridos formativos demuestran una "voluntad" de integrarse ${ }^{11}$. Por otro lado, en la medida en que las titulaciones del lugar de instalación tienen mayor valía que las del país de emigración, le significa una referencia a la hora de buscar empleo.

Pero, además, se reinvindica el aprendizaje de los conocimientos adquiridos en la formación. A pesar de que es muy común que las personas entrevistadas poseen conocimientos previos relacionados con el proceso formativo, éste brinda la oportunidad de sistematizarlo y ampliarlo. Esto se pone de manifiesto en las siguientes citas:

Claro. ¿Y tú en Marruecos habías trabajado de soldador? Sí, cinco años trabajando ahí. ¿Y te sirvió lo que sabías? Sí, me sirvió mucho. Yo llegué aquí directamente a trabajar en la empresa. Oficial, directamente. $[\ldots]$ ¿..Encuentras que te ha servido más este curso? Para reforzar mi trabajo, antes yo sabía soldar, una soldadura, pero no sabía muchas cosas el tipo de gas, tipo de material, electrodos, hilo, cómo se llaman los tipos de hilo, muchas máquinas nuevas. Muchas cosas, entonces, esto en combinación con lo otro, puede hacer un conjunto de formación

10 Desde un abordaje metodológico de tipo cuantitativo, esto también lo señala el ya citado trabajo de Valiente, Zancajo y Tarriño (2014) donde se afirma que desde el inicio de la crisis económica y el consecuente desempleo, el curso de estudios 2007-2008 ha incrementado la participación en los estudios posobligatorios en Cataluña. Es preciso recordar que incluso las prestaciones dirigidas a desempleados se encuentran sujetas a la consecución de itinerarios de inserción que incluyen procesos formativos.

11 Estos certificados, muchas veces, tienen mayor valor que otras acreditaciones adquiridas antes de emprender el proceso migratorio. Además, aquellos sirven para dar cuenta del arraigo social de la persona que ha realizado el curso. 
buena [...] Bueno, en mi trabajo cojo una pieza y sueldo, pero no tengo mucha, mucha, formación de la pieza, el tipo de material, tipo de gas, ¿sabes? Regulo la máquina a ojo, y pum. Ahora, pum, pum, pum. Yo sé que tengo una chapa, de amperio, tipo de gas, electrodo o hilo, muchas cosas ¿sabes? Sí, sí. Entonces es más fácil. Por ejemplo, si viene un encargado o jefe y te pregunta cómo lo haces, antes era, cojo y empiezo a probar. Y esto hay que hacerlo así y así, y ahora directamente. [...] Sí, ahora por ejemplo en el currículum, voy a poner, estudié tanto tiempo de soldador, tengo experiencia y encima tengo un curso, y entonces tengo más formación, el curso, currículum, ¿sabes? Muchas empresas miran si ha tenido algún curso o no. Si una persona hace un curso tiene más ¿cómo dice? Práctica y teoría. Si el trabajo tienes práctica, te falta teoría. La mayoría de gente que está en una obra, están trabajando, tienen práctica, pero aquí hacemos teoría [...] Tienes más formación y más posibilidades, ¿sabes? Por ejemplo, si voy a hacer una entrevista de trabajo hablo de la formación, le hablo con los nombres, antes no sabía los nombres de muchas cosas [...]". (Entrevista con un usuario del curso de soldadura de una fundación de Formación Profesional para el Empleo vinculada a un sindicato).

La instancia de formación también puede ofrecer la posibilidad de ampliar los conocimientos que ya se llevan a cabo como una manera de enriquecer la propia profesión:

Pues a ver, yo ya tenía conocimientos de pintura, como te comenté. Trabajé en pintura, [en el curso] aprendí una que otra técnica nueva que no la había usado, pero sí sabía que existía, [...] sí aprendí unas técnicas nuevas [...]. (Entrevista con el usuario del curso de pintura de una fundación vinculada con la Iglesia Católica).

A pesar de que los entrevistados tenían conocimientos de los contenidos impartidos, reconocen sacar partido a los cursos de formación.

Por otra parte, además, en los cursos también es posible adquirir "conocimientos prácticos" trasmitidos por los formadores que no son necesariamente conocimientos técnicos. Tales conocimientos se refieren, por ejemplo, a cómo afrontar un trabajo, cómo orientarse en él, cómo calcular un presupuesto, cómo tratar con los empleadores, etc.

Las preguntas siguientes son cómo tiene que cobrar, qué tiene que hacer y todo eso. A partir de la semana que viene, subo una vez a la semana y hay una pizarra les hago un croquis y hago unas medidas y pongo por metros, los metros que se gastan de pintura, qué se tiene que gastar y cómo tienen que cobrar, por tantos metros y todo eso, y ahí van tomando nota. Claro. Si estoy aquí vienen y preguntan si se pierden un poco con algún trabajo. Vino uno que le había salido un trabajo en una estructura muy grande y el piso eran como vigas y tal, cómo se podía cobrar eso. Y eso es difícil para mí, que tienen que calcular y hay que calcular mucho, entonces hay varias formas, si el cliente te pone el material, hay dos formas de cobrar, o le cobras por horas o le cobras por días, si le cobras por días, normalmente te pueden dar 40- 45 por día. Por horas o las horas son muy bajitas, que sea una relación que me va salir un sueldo de 35-40. (Entrevista con el formador del curso de pintura de la fundación vinculada con la Iglesia Católica). 
En los cursos de formación para la realización de tareas del hogar, también se trasmitían conocimientos en relación con los montos mínimos para cobrar tal trabajo, así como también parámetros de las tareas a realizar en determinado tiempo laboral. También se trasmitían estrategias para evitar abusos por parte de la "señora" dueña de casa.

Este conocimiento a partir de la experiencia de los formadores es muy valorado ante un eventual trabajo. Además, como veremos en el siguiente fragmento de entrevista, el formador también hace recomendaciones acerca de cómo mantener las relaciones con los posibles clientes para poder organizarse y no perder encargos en un tipo de trabajo que es autónomo:

Yo voy a hacer el presupuesto, yo voy a hacer el trabajo, a veces, te han llamado muchas veces, sobre todo en comunidades, escaleras, fachadas, pues esto sí que se tarda bastante, porque te llaman de cuatro, cinco o seis, y de esas te sale sólo una, pero dices, me ha salido una y tengo tres días o cuatro para hacer una escalera, de cinco, seis pisos, pues tienes calculado de allí, pero tienes más presupuestos, en ese momento te sale un piso, que te llaman que "me estado mirando el presupuesto y hemos decidido que sí". ¿Qué ocurre con eso? Que miras las fechas, y en seguida te está presionando, te está diciendo es que yo ya, yo quiero que vengas al piso, entonces tienes la gente metida en un trabajo y tú no la puedes sacar de allí, porque aquel señor te está presionando para que vayas a hacerle el trabajo. ¿Qué ocurre? Le dices "una semana o quince días", no me contratan, entonces tienes que jugar, tienes que decirle, lo siento mucho, ¿cuánto me puede esperar?, ¿diez o quince días?, ya te presiona un poco, si van a esperar quince días ya le dices diez, no le puedes decir veinte, porque dice, tanto tiempo no le espero, pierdes el cliente, entonces tienes que jugar un poco con esto. Es el subibaja. (Entrevista con el formador del curso de pintura de la fundación vinculada con la Iglesia Católica).

Estas recomendaciones y conocimientos prácticos son muy valorados como parte de la formación; esto es, la explicitación de saberes fundamentales para el efectivo desarrollo de posibles trabajos, tan necesarios como los conocimientos técnicos para poder llevarlos a cabo.

Por todo lo dicho hasta aquí, queremos sugerir que, en relación con la formación para la inserción laboral de las personas inmigrantes, es preciso tener unas expectativas mucho más modestas que las enunciadas por los planes y programas de integración, sólo así serán más ajustadas a los procesos concretos de la formación para la inserción laboral de las personas inmigrantes.

\section{Conclusión}

A la luz de lo dicho, consideramos que es necesario matizar el carácter unilateralmente positivo de la formación para la inserción laboral de las personas inmigrantes. En este sentido, es preciso reconocer los límites que se encuentran presentes en dicha estrategia de intervención. Tal ejercicio no supone desconocer la potencia que dicha estrategia posee, pero consideramos imprescindible atender a los elementos iluminados desde las prácticas formativas concretas, para ganar en comprensión acerca de sus posibilidades efectivas. 
Por un lado, la propia normativa de control de los flujos migratorios pone coto a las expectativas generadas por la formación: el establecimiento de los cupos de puestos de trabajo disponibles para acceder a una residencia regular impone, desde el inicio, límites a las capacidades de inserción de las personas inmigrantes. Así pues, encontramos una doble atadura en cuanto a las posibilidades efectivas de la formación para la inserción laboral. Por un lado, la normativa migratoria, que atendiendo a las demandas del mercado laboral decide qué tipos de (trabajadores) inmigrantes son necesarios. Además, hemos reconocido cómo el tipo de estructura productiva puede asentarse en la necesidad de formación o, más bien, todo lo contrario. Se ha puesto de manifiesto cómo ciertos sectores productivos requieren escasas competencias formativas de sus trabajadores, que coincidentemente se trata de sectores con escaso valor social, que brindan pocas oportunidades a quienes se ocupan de ellos.

La necesidad de ofrecer una visión más modesta de lo que se puede esperar de la formación para la inserción laboral, no significa un menoscabo de ésta como estrategia de intervención. Ella ofrece valiosos conocimientos para las personas inmigrantes ya que, brinda la posibilidad de sistematizar y enriquecer conocimientos previos, así como también conocer las experiencias prácticas de los formadores muy útiles para el futuro trabajo. Hay que mencionar que, más allá de los contenidos formativos, los procesos de formación aportan un entramado y una vinculación social que promueven dinámicas socialmente inclusivas.

Sin embargo, los estimables aportes que se realizan desde los recursos de formación no reemplazan las funciones que el trabajo cumple en la vida de las personas. Ni la centralidad integradora que continúa teniendo el trabajo.

Por todo lo dicho, es preciso apelar a cierta "modestia" en cuanto a las expectativas sobre esta estrategia para que no se vuelva un disimulador de graves dificultades de las propias sociedades de instalación de las personas inmigrantes tales como el desempleo, las formas segmentadas en la estructura productiva e incluso la persistente visión pragmática de la inmigración, presencia sólo se justifica en la medida en que es "útil" y ofrece ventajas comparativas a la sociedad en la que se instala.

En este sentido, consideramos que continúa vigente y es más necesario aún poner en la agenda de la investigación social los modos en los que la sociedad propone la promoción social, como garante de la integración social. Para evitar generar efectos no esperados o incluso contrarios a los objetivos originalmente planteados por ellas como, por ejemplo, el refuerzo de los lugares de inclusión diferenciada (Mezzadra, 2007) o la responsabilización individual de los sujetos que padecen procesos de exclusión social.

\section{Referencias bibliográficas}

Aguilar Idáñez, M. J. (2011). “Integración laboral de inmigrantes: experiencias europeas de éxito y buenas prácticas en formación para el empleo", en Panel 3 Inmigración, integración y políticas sociales en época de crisis económica y financiera. Actas del III Congreso Anual de la REPS. Pamplona: Universidad de Navarra (en línea). http://www.unavarra. es/digitalAssets/149/149683_1000004_AguilarIda-n-ez_Formacio-Empleo_fulltext.pdf [consulta 5 Febrero de 2012].

Alonso, L. E. (2007). La crisis de la ciudadanía liberal. Barcelona: Anthropos. 
Bertaux, D. (2005). Los relatos de vida: perspectiva etnosociológica. Barcelona: Bellaterra.

Carrasco, C.; Ruiz, B. y Martínez, E. (2006). Metodología para la inserción laboral de personas inmigrantes. Madrid: Red Acoge.

Casey, J. (1995). El Papel de las organizaciones no gubernamentales en la elaboración de las políticas públicas: el caso de la integración de inmigrantes extranjeros en Cataluña. Gomà, R. (dir.), Facultad de Ciencias Políticas y Sociología, Universidad Autónoma de Barcelona, Barcelona.

Castel, R. (1997). Las Metamorfosis de la cuestión social: una crónica del salariado. Buenos Aires: Paidós.

Diario Electrónico del Gabinete de Comunicación Ministerio de Trabajo e Inmigración (2010). "Nuevas capacidades para nuevas ocupaciones para una Europa más competitiva" (en línea). http://www.tt.mtin.es/eu2010/es/noticias/empleo/201004/EMP20100408002.html [consulta 9 de abril de 2010].

Fernández Enguita, M. (1990). Educación, formación y empleo en el umbral de los noventa. Madrid: Centro de Publicaciones del Ministerio de Educación y Ciencia.

Ferrera, M. (1996). "The 'Southern Model' of Welfare in Social Europe". Journal of European Social Policy. 6 (1): 17-37.

Fundación Tripartita, (2010). Web de la fundación (en línea). http://www.fundaciontripartita. org/index.asp? $\mathrm{MP}=12 \& \mathrm{MS}=29 \& \mathrm{MN}=1$ [consulta 3 de Enero de 2010]

García-Cano Torrico, M. (2002). "Formación ocupacional y promoción de igualdad de género en España extracomunitaria”. En García-Cano, M.; Gregorio Gil, C. y Agrela, B. (coords.) Mujeres de un solo mundo: globalización y multiculturalismo (pp. 315-353). Granada: Universidad de Granada.

García-Cano Torrico, M. (2003). "Formación ocupacional e inmigración. Un análisis antropológico sobre la construcción de la diferencia y sus implicaciones en las prácticas". Revista interamericana de educación de adultos. 25 (2): 11-36.

Gil Araujo, S. (2010). Las argucias de la integración. Políticas migratorias, construcción nacional y cuestión social. Madrid: Iepala.

Herrera, E. (1994). "Reflexiones en torno al concepto de integración en la sociología de la inmigración". Papers. 43: 71-76.

Darmon, I., Frade, C., Demazière, D. Haas, I. (2006). "Formadores y usuarios frente al doble vínculo de la formación para la empleabilidad". Cuadernos de Relaciones Laborales. 24 (2): 37-62.

Foro para la Integración Social de los Inmigrantes (2007). Informe sobre la situación de la integración social de los inmigrantes y refugiados en 2007, Ministerio de Trabajo y asuntos sociales, Secretaría de Inmigración y emigración, Dirección General de Integración de los inmigrantes (en línea). http://www.observatoripalma.org/imgdb//archivo_doc7828. pdf [consulta 3 de septiembre de 2009].

Foro para la Integración Social de los Inmigrantes (2008). Informe sobre la situación de la integración social de los inmigrantes y refugiados en 2008, Ministerio de Trabajo y asuntos sociales, Secretaría de Inmigración y emigración, Dirección General de Integración de los inmigrantes (en línea). http://www.observatoripalma.org/ [consulta 3 de septiembre de 2009].

Laparra Navarro, M. (ed.) (2003). Extranjeros en el purgatorio: integración social de los inmigrantes en el espacio local. Barcelona: Bellaterra.

López Sala, A. M. (2005). Inmigrantes y Estados: la respuesta política ante la cuestión migratoria. Barcelona: Anthropos.

Navarro, V. (2006). El subdesarrollo social de España: causas y consecuencias. Barcelona: Argumentos, Anagrama. 
Mora Castro A. (2007). "Inmigración, servicios públicos e integración social”. Cuadernos de Trabajo Social. 20: 25-34.

Mezzadra, S. (2007). “Confini, migrazioni, cittadinanza”. Papers. 85: 31-41.

Moreno, L. (2002). "Bienestar mediterráneo y 'supermujeres"”. Revista Española de Sociología. 2: 41-57.

Moreno, L. y Serrano Pascual, A. (2007). “Europeización del Bienestar y activación”. Politica y Sociedad. 44(2): 31-44.

Oliver Grasiot, E. (2015). "ONG, crisis económica e ideología. Aproximación a los efectos de los 'recortes' a través del estudio de caso de la ONG AlterNativa. Intercanvi amb els Pobles Indígenes". Perifèria revista de recerca i formació en antropología. 20 (1): 56-84.

Pajares, M. (2005). La integración ciudadana. Una perspectiva para la inmigración. Barcelona: Icaria.

Plan Estratégico de Ciudadanía e Integración 2007- 2010 (2007). Ministerio de Trabajo y Asuntos Sociales, Secretaría de Estado de Inmigración y Emigración, (en línea). http://extranjeros.empleo.gob.es/es/IntegracionRetorno/Plan_ estrategico/pdf/PECIDEF180407. pdf [consulta 2 de julio de 2008].

Plan Estratégico de Ciudadanía e Integración 2011-2014 (2011). Ministerio de Trabajo y Asuntos Sociales, Secretaría de Estado de Inmigración y Emigración, (en línea). http:// extranjeros.empleo.gob.es/es/IntegracionRetorno/ Plan_estrategico/pdf/ [consulta 10 de diciembre de 2011].

Rodríguez Cabrero, G. (2003). "Situación actual y perspectivas de desarrollo d las organizaciones voluntarias de acción social en el Estado de bienestar". Documentación Social. 132: 203-229.

Sainsbury, D. (2006). "Immigrants' social rights in comparative perspective: welfare regimes, forms of immigrationn and immigration policy regimes". Journal of European Social policy. 16(3): 229-244.

Sanahuja i Velez, R. (2010). "El impacto social de la crisis. El papel del mundo local en la integración de la inmigración. Estudio de caso de Barcelona". En Inmigración y crisis económica. Impactos actuales y perspectivas de futuro. Anuario de la inmigración en España (pp. 73-106). Bellaterra: Cidob.

Santamaría, E. (2007). "Sobre la utilidad de los inmigrantes". Archipiélago. Cuadernos de crítica de la cultura. 77-78: 6-7.

Sayad, A. (2010). La doble ausencia: de las ilusiones del emigrado a los padecimientos del inmigrado. Barcelona: Anthropos.

Sennett, R. (2000). La corrosión del carácter: las consecuencias personales del trabajo en el nuevo capitalismo. Barcelona: Anagrama.

Shore, C. y Wright, S. (eds.) (1997). Anthropology of policy. Critical perspectives on governance and power. London: Routledge.

Valiente, O.; Zancajo, A. y Tarriño, A. (2014). La formació professional i l'ocupació a Catalunya. Una ullada als indicadors des d'una perspectiva comparada Barcelona: Edicions els Llums.

Yufra, L.C. (2012). Inmigrantes en formación: Estado de bienestar y promoción de lazos sociales en el caso de la formación para la inserción laboral de las personas inmigrantes en Barcelona. Santamaría, E. (dir.), Facultad de Psicología Social, Universidad Autónoma de Barcelona, Barcelona.

Yufra, L. C. (2016). "El trabajo que no se ve. Dispositivos de inserción sociolaboral para mujeres inmigrantes en Barcelona”. Empiria. Revista de metodología de ciencias sociales, 33: $15-36$. 